\title{
EFEITO DO MANEJO DE CAPIVARAS NA OCORRÊNCIA DE CARRAPATOS EM ÁREAS COM TRÂNSITO DE HUMANOS
}

\section{CAPYBARAS MANAGEMENT EFFECT ON OCCURRENCE OF TICKS IN AREAS WITH PEOPLE MOVEMENT}

\author{
Francisco de Assis Neo ${ }^{1}$; José Sávio Colares de Melo ${ }^{1}$ \\ ${ }^{1}$ Pesquisadores do Instituto Chico Mendes de Conservação da Biodiversidade, Centro \\ de Pesquisa e Conservação de Peixes Continentais, Pirassununga, SP. E-mail: \\ francisco.neo@icmbio.gov.br e jose-savio.melo@icmbio.gov.br
}

\begin{abstract}
RESUMO
O objetivo deste trabalho foi analisar o efeito do manejo de capivaras com relação à ocorrência e dispersão de carrapato em áreas com circulação e trânsito de humanos. Entre os meses de dezembro de 2008 e março de 2009, foram instalados 2.200 metros de alambrado nos limites entre as áreas florestadas e as áreas de tanques, viveiros e laboratórios no CEPTA (Centro Nacional de Pesquisa e Conservação de Peixes Continentais), localizado em Pirassununga/SP, Brasil, para reter as capivaras. Observou-se queda acentuada de ocorrências de carrapatos em humanos, nas áreas em que as capivaras estiveram impedidas de acesso. O manejo de capivaras por meio do impedimento de acesso às áreas de maior circulação de humanos diminui a ocorrência de carrapatos nessas áreas e, consequentemente, previne doenças por eles transmitidas.
\end{abstract}

Palavras-chave: Manejo de animais silvestres. Hydrochaeris hydrochaeris. Carrapato. Gênero Amblyomma.

\begin{abstract}
Effect of capybaras management on ticks' occurrence in areas with people movement was analyzed. Between the months of December 2008 and March 2009 were installed 2200 meters of fencing at the limits between the areas forested and tanks, ponds and laboratories areas at CEPTA (Research and Conservation National Center for Continental Fish), located in Pirassununga/SP, Brazil, to retain capybara. It was observed decrease in the occurrence of ticks in people, in areas where capybaras were prevented to access. The management of capybaras by preventing access to areas of greatest movement of people decrease ticks occurrence and avoid diseases caused by them.
\end{abstract}

Keywords: Wild animals management. Hydrochaeris hydrochaeris. Tick. Amblyomma genus.

\section{INTRODUÇÃO}

A capivara, Hydrochaeris hydrochaeris Linnaeus (Rodentia: Caviidae) (ROWE e HONEYCUTT, 2002), é uma espécie da fauna silvestre encontrada em quase todo o território 
nacional. Ocorre no Panamá e na América do Sul, com exceção do Chile, até a bacia do rio Uruguai, na Argentina, e não é encontrada a grandes altitudes (MACDONALD, 1981; ALHO, 1982; TOMAZZONI, 2003; GARCIAS e BAGER, 2009; JACOMASSA, 2010). Habitam matas ciliares, savanas sazonalmente inundáveis, manguezais (MONES e OJASTI, 1986), e áreas com elevado grau de interferência antrópica (FERRAZ et al., 2001). São mais ativas à tarde e início da noite (OLIVEIRA e BONVICINO, 2006).

No Estado de São Paulo, algumas populações de capivara se encontram em excedente populacional, causando danos agrícolas, além de riscos à saúde pública pela infestação de ectoparasitos e a consequente disseminação de zoonoses (VARGAS et al., 2007).

A espécie está associada à ocorrência de febre maculosa por ser hospedeira do carrapatoestrela, Amblyomma cajennense Fabricius (Acari: Ixodidae) que é vetor biológico e reservatório natural de bactérias do gênero Rickettsia (Rickettsiales: Rickettsiaceae), agente etiológico da febre maculosa (LABRUNA et al., 2001; SANGIONI et al., 2005).

A febre maculosa brasileira (FMB), causada por Rickettsia do grupo da febre maculosa e transmitida por carrapatos, é similar à febre maculosa das Montanhas Rochosas que tem como agente Rickettsia rickettsii (ESTRADA et al., 2006), sendo a FMB uma doença de notificação obrigatória e frequentemente fatal e que tem preocupado as autoridades sanitaristas de forma crescente (FERREIRA, 2006; SILVA, 2009). Essa doença ocorre principalmente no Sudeste do país, com destaque para os Estados de Minas Gerais e São Paulo (ESTRADA et al., 2006). Além dessa doença, os carrapatos podem causar paralisias, toxicose, reações alérgicas e são vetores de ampla gama de patógenos virais, bactérias e protozoários (ESTRADA-PEÑA e JONGEJAN, 1999).

A necessidade de manejar capivaras em algumas regiões do Estado de São Paulo é urgente, pois os recursos hídricos e florestais pertinentes à sobrevivência da espécie como corpo d'água, área de pasto e mata, são abundantes, tornando o crescimento populacional da espécie incompatível à atividade humana (VARGAS et al., 2007).

O objetivo deste trabalho foi analisar o efeito da retenção de capivaras na ocorrência de carrapatos em áreas com circulação e trânsito de humanos no Centro Nacional de Pesquisa e Conservação de Peixes Continentais - CEPTA, tendo como premissa a informação que, nesses locais, a capivara é o maior responsável pela disseminação do carrapato.

\section{MATERIAL E MÉTODOS}

O estudo foi conduzido no Centro Nacional de Pesquisa e Conservação de Peixes Continentais - CEPTA/ICMBio, localizado em Pirassununga, Estado de São Paulo $\left(21^{\circ} 56^{\prime} \mathrm{S}, 4^{\circ}\right.$ 22' W), a $555 \mathrm{~m}$ de altitude. A área total do CEPTA é de $272 \mathrm{hm}^{2}$, dividida em duas subáreas: A, com $86 \mathrm{hm}^{2}$, e B, com $186 \mathrm{hm}^{2}$ (Figura 1), sendo que o estudo foi realizado na subárea B, cuja área cercada representa aproximadamente $21,5 \%$ dessa subárea, ou seja, $40 \mathrm{hm}^{2}$ (Figura 2).

Durante o período de julho de 2008 a junho de 2010, 80 voluntários, constituídos por funcionários e visitantes do CEPTA, foram orientados a informar as ocorrências de carrapatos detectados em contato com o corpo, informando o estádio de desenvolvimento: se adulto, conhecido como estrela ou rodoleiro; ninfa, conhecido como vermelhinho; ou larva, conhecida como micuim; o dia da detecção; o número de organismos observados; se estavam andando (livres) ou sugando (fixos).

Entre os meses de dezembro de 2008 e março de 2009, nos limites entre as áreas dos tanques, viveiros e laboratórios e as áreas florestadas e represas, foram instalados 2.200 metros de alambrado, confeccionado com telas de arame galvanizado, fio 12, malha de $10 \mathrm{~cm}$ e $1,5 \mathrm{~m}$ de altura, para impedir a passagem das capivaras e a sua permanência nas áreas de maior circulação de 
humanos no CEPTA, porém preservando seu hábitat natural, com territórios propícios á alimentação, proteção, repouso e reprodução (Figura 3).

Durante o período estudos, foram obtidos dados trimestrais de precipitação pluviométrica acumulada $(\mathrm{mm})$ e temperatura média do $\operatorname{ar}\left({ }^{\circ} \mathrm{C}\right)$ para a região onde se localiza o CEPTA, a partir de informações meteorológicas fornecidas pela Divisão de Meteorologia Aeronáutica (DMET) localizada na Academia da Força Aérea (AFA) de Pirassununga/SP.

Os dados originais obtidos foram tabulados e organizados por trimestre, por fase de crescimento e por área de ocorrência. Foram realizadas análises gráficas dos dados disponíveis.
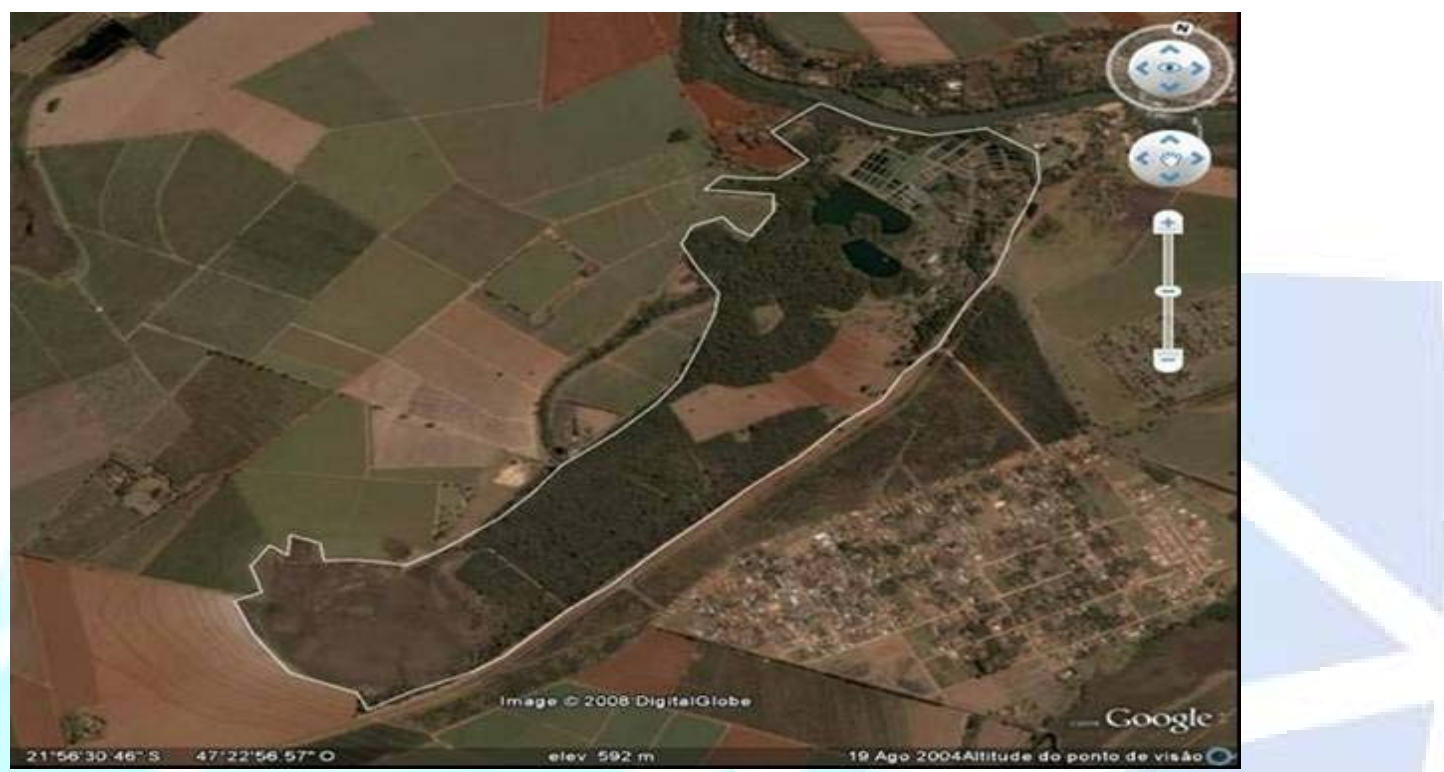

Figura 1. Perímetro da área do Centro Nacional de Pesquisa e Conservação de Peixes Continentais CEPTA, onde os estudos foram realizados.

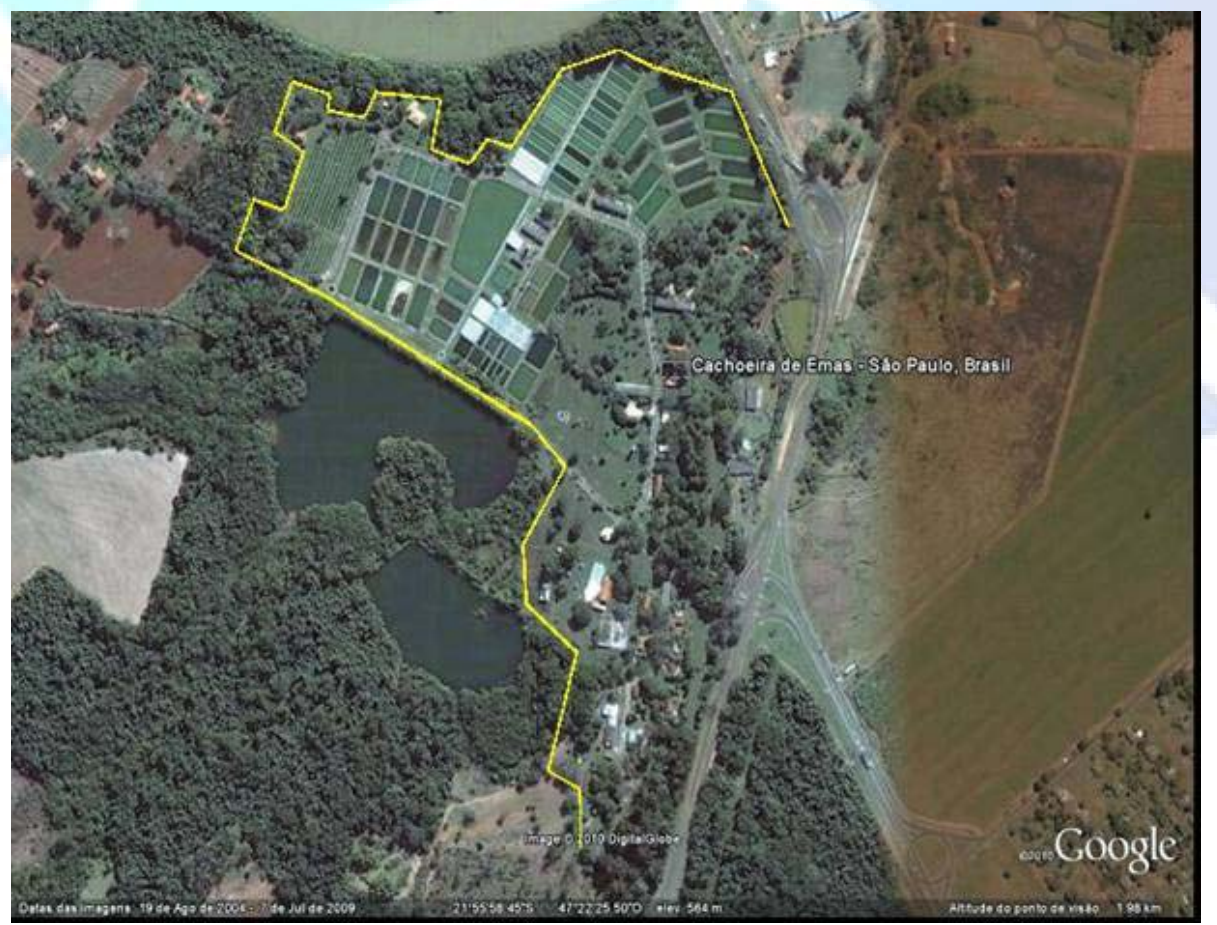

Figura 2. Perímetro de área de uso intensivo do Centro Nacional de Pesquisa e Conservação de Peixes Continentais - CEPTA, cercada com alambrado para impedir o acesso de capivaras (Hydrochaeris hydrochaeris Linnaeus). 


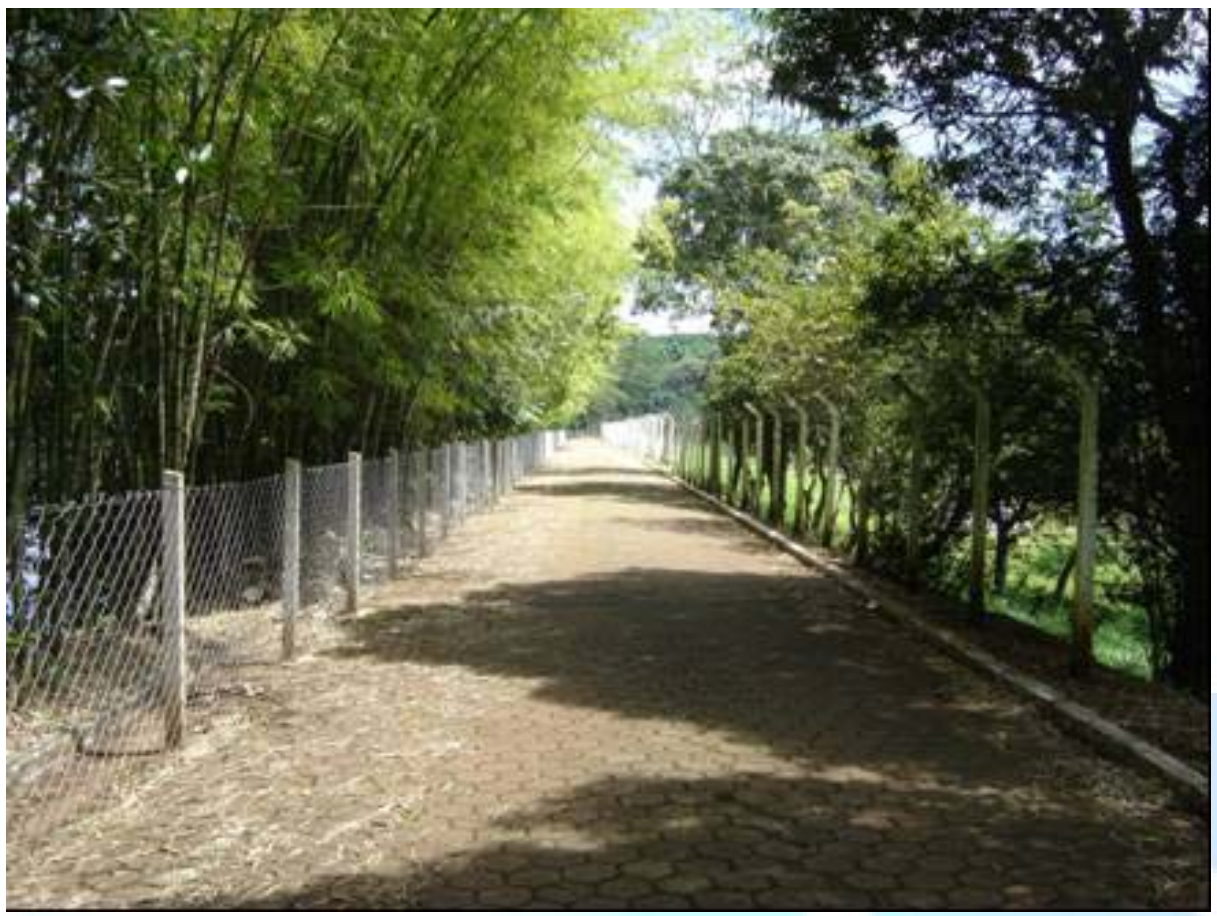

Figura 3. Cerca de alambrado instalada em trecho da área do Centro Nacional de Pesquisa e Conservação de Peixes Continentais - CEPTA. (Foto: Francisco de Assis Neo).

\section{RESULTADOS E DISCUSSÃO}

Acima de $87,2 \%$ dos carrapatos detectados pelos voluntários foram observados no período de julho/2008 a junho/2009. O restante dos carrapatos, cerca de 12,6\%, nos meses de julho a setembro de 2009 . No período de outubro/2009 a junho/2010, foi relatada a ocorrência de apenas um carrapato adulto (Tabela 1).

Tabela 1 - Frequência absoluta de carrapatos do gênero Amblyomma por estádio de desenvolvimento, por trimestre e a forma como foram detectados (livres ou fixos) nos voluntários no Centro Nacional de Pesquisa e Conservação de Peixes Continentais - CEPTA, no período de julho de 2008 a junho de 2010.

\begin{tabular}{cccccccc}
\hline \multirow{2}{*}{ Período } & \multicolumn{2}{c}{ Adultos } & \multicolumn{2}{c}{ Ninfas } & \multicolumn{2}{c}{ Larvas } & Total \\
\cline { 2 - 7 } & livres & fixos & livres & fixos & livres & fixos & \\
\hline jul-set/08 & 6 & 3 & 233 & 152 & 550 & 50 & 994 \\
out-dez/08 & 12 & 2 & 72 & 104 & 0 & 0 & 190 \\
jan-mar/09 & 44 & 5 & 0 & 0 & 0 & 0 & 49 \\
abr-jun/09 & 11 & 2 & 0 & 2 & 809 & 43 & 867 \\
jul-set/09 & 0 & 0 & 0 & 4 & 301 & 0 & 305 \\
out-dez/09 & 0 & 0 & 0 & 0 & 0 & 0 & 0 \\
jan-mar/10 & 0 & 1 & 0 & 0 & 0 & 0 & 1 \\
abr-jun/10 & 0 & 0 & 0 & 0 & 0 & 0 & 0 \\
\hline Total & 73 & 13 & 305 & 262 & 1.660 & 93 & 2.406 \\
\hline
\end{tabular}


A frequência de carrapatos em humanos por trimestre, durante o período de estudos, foi maior nos meses de julho a setembro de 2008 e abril a junho de 2009 , coincidindo com os períodos de menor intensidade de chuvas e de temperaturas médias mais baixas, e menor frequência nos demais períodos até setembro de 2009; de outubro de 2009 a junho de 2010, praticamente foi nula a ocorrência de carrapatos na área isenta de capivaras (Figuras 4 e 5). Esses resultados são semelhantes aos encontrados por Ribeiro et al. (2010) na Serra do Cipó, em Minas Gerais, que encontraram grande quantidade de ninfas e larvas na estação seca e início do verão.

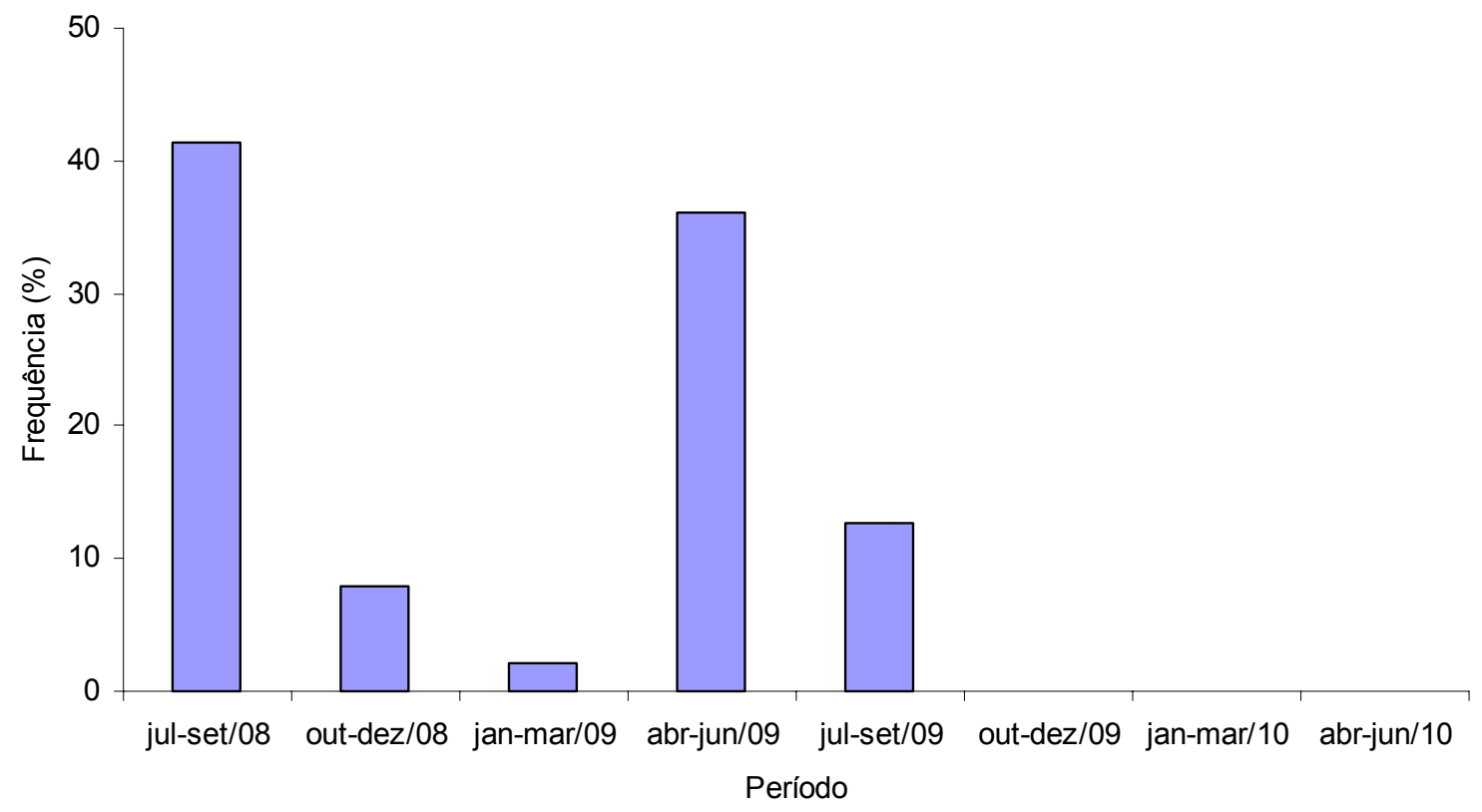

Figura 4. Frequência relativa de carrapatos do gênero Amblyomma detectados em voluntários no Centro Nacional de Pesquisa e Conservação de Peixes Continentais - CEPTA, por trimestre, no período de julho de 2008 a junho de 2010.

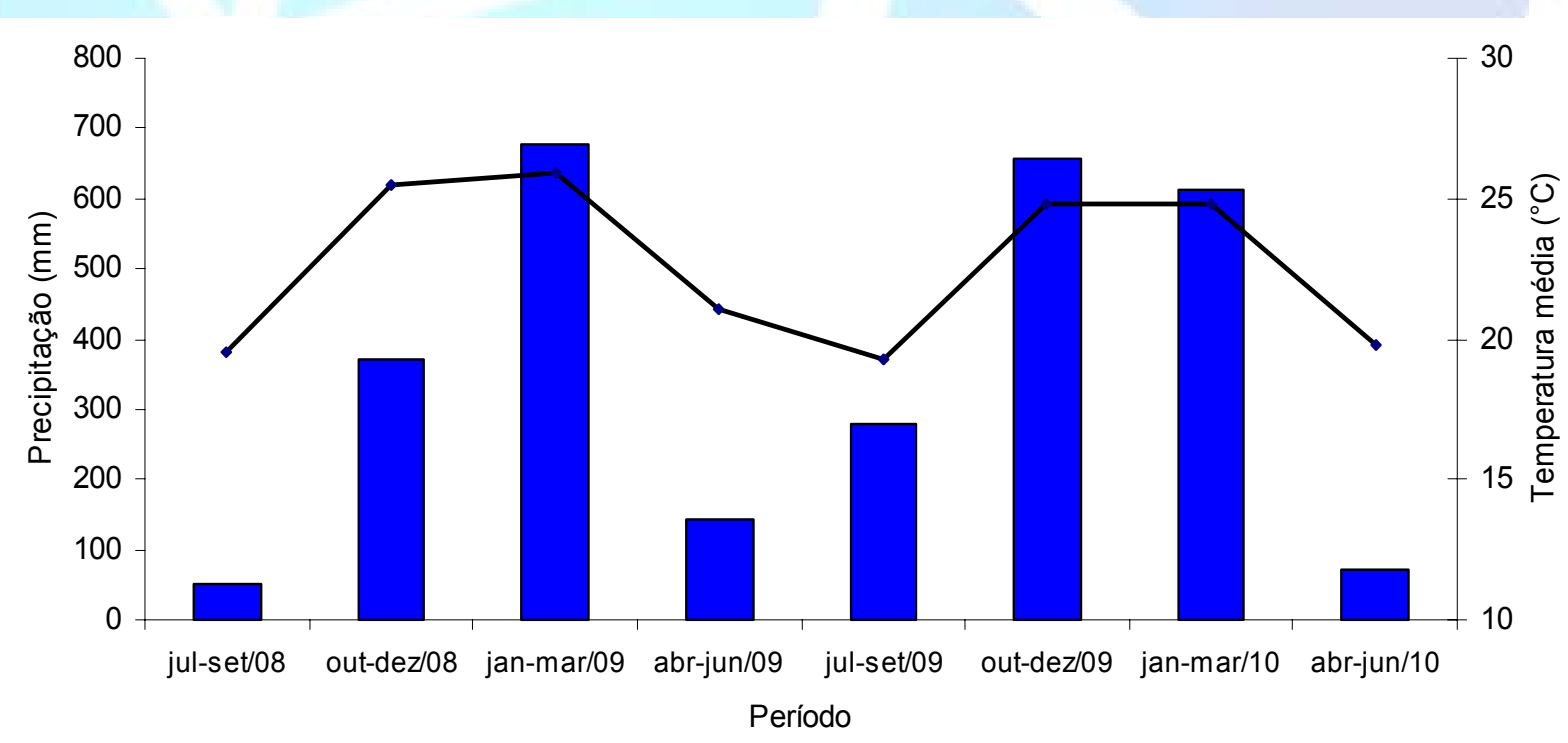

Precipitação $\rightarrow$ Temparatura média

Figura 5. Precipitação pluviométrica acumula por trimestre e temperatura média por trimestre registradas na região do Centro Nacional de Pesquisa e Conservação de Peixes Continentais - CEPTA, por trimestre, no período de julho de 2008 a junho de 2010. 
O número de carrapatos observados livres foi maior do que o número de parasitos fixos. Observou-se também que o número de carrapatos nos diversos estádios de desenvolvimento variou inversamente com o tamanho dos indivíduos (Figura 6).

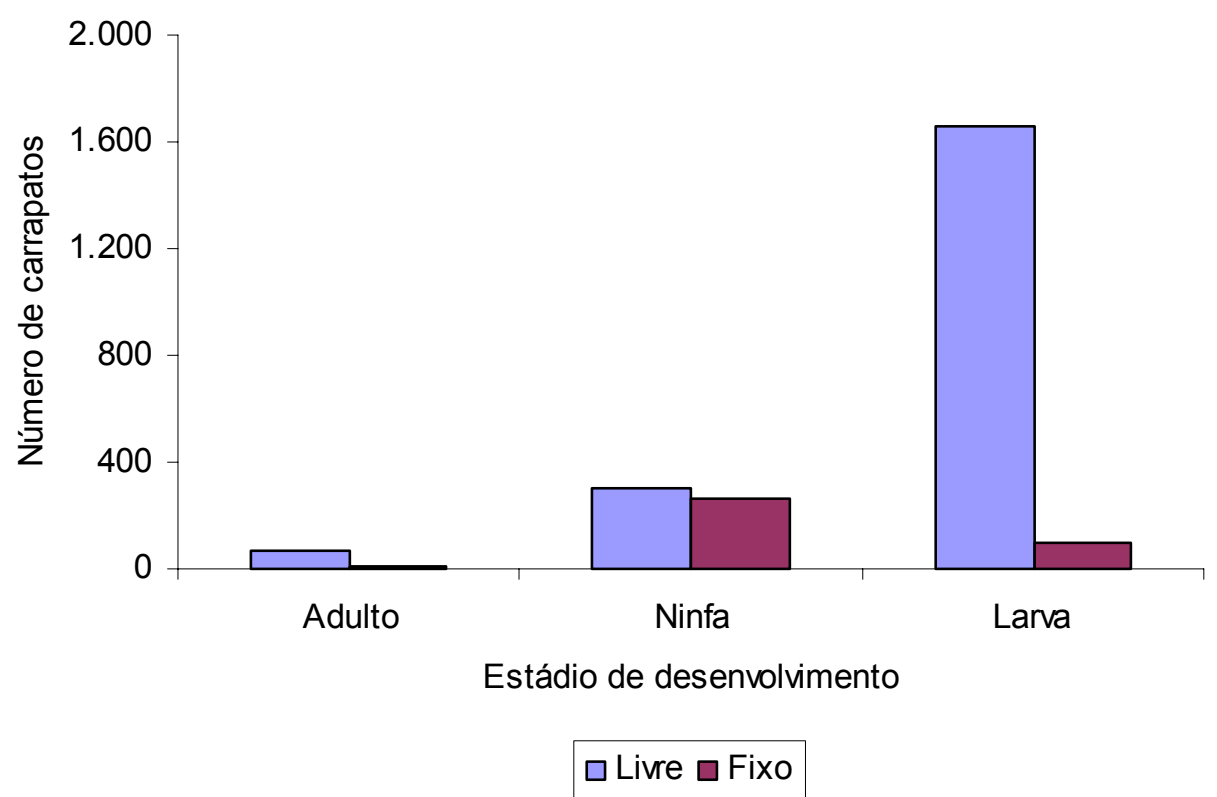

Figura 6. Número de carrapatos do gênero Amblyomma por estádio de desenvolvimento, observados livres ou fixos em voluntários no Centro Nacional de Pesquisa e Conservação de Peixes Continentais - CEPTA, no período de julho de 2008 a junho de 2010.

A área de vivência de capivaras no CEPTA, antes da colocação dos alambrados, foi estimada em $35,3 \mathrm{hm}^{2}$ (VARGAS, 2005). Após a colocação do alambrado, as capivaras deixaram de ocupar parte dessa área e passaram a ocupar outros locais, incluindo aqueles onde não havia registros de sua ocorrência, como as áreas de cultivo de cana-de-açúcar em duas propriedades vizinhas, onde foram observados danos.

Estudo realizado no CEPTA por Vargas et al. (2007), registrou de 12 a 29 indivíduos avistados e apontou densidade ecológica total de capivara variando de 0,34 a $0,82 \mathrm{ind} . / \mathrm{hm}^{2}$ por mês durante o período, sendo que as classes etárias em que se observaram as maiores densidades ecológicas foram a adulta (maio) e a de filhotes (outubro), ambas com $0,40 \mathrm{ind} . / \mathrm{hm}^{2}$ por mês. Garcias e Bager (2009) encontraram densidade de 5,1 ind. $/ \mathrm{hm}^{2}$ na Estação Ecológica do Taim, enquanto Jacomassa (2010) registrou densidade de 2,2 ind. $/ \mathrm{hm}^{2}$ no Pantanal do Miranda, Mato Grosso do Sul.

Perez et al. (2008), investigando as relações entre os carrapatos do gênero Amblyomma (Acari: Ixodidae) com os hospedeiros na ESALQ/USP de Piracicaba, São Paulo, concluíram que as capivaras e os gambás concentraram a quase totalidade de carrapatos da mastofauna avaliada, sendo as capivaras parasitadas em sua maioria por adultos $A$. cajennense, e somente uma pequena porcentagem correspondeu a $A$. dubitatum.

No presente trabalho, as capivaras não tiveram mais acesso à área cercada e houve diminuição gradual dos carrapatos parasitando humanos. Isso pode sugerir que a utilização de cercas de alambrado na retenção de capivaras pode funcionar muito bem para o manejo de áreas sujeitas à ocorrência destes animais e seus ectoparasitos associados e que podem afetar a saúde dos humanos. São exemplos destes locais, os parques e jardins públicos municipais, unidades de conservação, universidades, jardins zoológicos, condomínios, entre outros. Nesse sentido, Pereira e Eston (2007) recomendaram cercar, com alambrado de 1,40 m, a área de uso público do Parque 
Estadual Alberto Löfgren, em São Paulo, como a melhor solução para acabar com a possibilidade de futuramente ocorrer um surto de febre maculosa nessa Unidade de Conservação. Também Ribeiro et al. (2010), que realizaram estudos envolvendo capivaras e carrapatos no Parque Nacional da Serra do Cipó, em Minas Gerais, afirmam que as trilhas mais visitadas pelos turistas e moradores devem ser manejadas de modo a reduzir o risco de exposição das pessoas aos carrapatos.

É importante considerar a possibilidade de a retenção ou impedimento de deslocamento de animais silvestres, como capivaras, resultar em mudança imediata da área de vivência desses animais, passando esses a se deslocar e ocupar áreas próximas e ocasionar outros tipos de problemas como atropelamentos e acidentes de trânsito, além do ataque às culturas agrícolas.

O cercamento de áreas para a retenção e impedimento do trânsito de animais silvestres, como o caso de capivaras, deve ser feito com base em estudo prévio da área de vivência dos bandos e, preventivamente, deve-se fazer monitoramento das populações submetidas ao manejo visando prever e reduzir problemas relacionados à movimentação desses animais para outras áreas. A altura e a malha da tela não podem impedir a movimentação de outras espécies de animais silvestres nativos, residentes ou em rota de migração.

\section{CONCLUSÔES}

O manejo de capivaras por meio do impedimento de acesso às áreas de maior circulação de humanos diminui a ocorrência de carrapatos nessas áreas e, consequentemente, previne doenças por eles transmitidas.

A cerca de alambrado impede a passagem de capivaras adultas, porém não impede a passagem de outros animais menores residentes ou em trânsito, o que pode ser benéfico para a conservação do ambiente e das espécies.

\section{AGRADECIMENTOS}

Pela colaboração e empenho de todos os servidores, funcionários e pessoas que de alguma forma contribuíram para o bom termo deste trabalho.

\section{REFERÊNCIAS}

ALHO, C.J.R. Brazilian rodents: their habitats and habits. In: MARES, M.A.; GENOWAYS, H.H. (Eds.) Mammalian biology in South America. Pittsburgh: University of Pittsburgh, 1982. p.143166.

ESTRADA, D.A.; SCHUMAKER, T.T.S.; SOUZA, C.E.; RODRIGUES NETO, E.J.; LINHARES, A.X. Detecção de riquétsias em carrapatos do gênero Amblyomma (Acari: Ixodidae) coletados em parque urbano do município de Campinas, SP. Revista da Sociedade Brasileira de Medicina Tropical, v. 39, n. 1, p. 68-71, 2006.

ESTRADA-PEÑA, A.; JONGEJAN, F. Ticks feeding on humans: a review of records on humanbiting Ixodoidea with special reference to pathogen transmission. Experimental and Applied Acarology, v. 23, n. 9, p. 685-715, 1999. 
FERRAZ, K.P.M.B.; SANTOS-FILHO, R.M.F.; PIFFER, T.R.O; VERDADE, L.M. Biologia e manejo da capivara: do controle de danos ao máximo rendimento sustentável. In: MATTOS, W.R.S. (Ed.) A produção animal na visão dos brasileiros. Piracicaba: Sociedade Brasileira de Zootecnia, 2001. p. 580-588.

FERREIRA, A.A. Carrapatos em roedores da região de Franca-SP: avaliação preliminar do potencial de transmissão de doenças infecciosas para a população humana. $2006.49 \mathrm{f}$. Dissertação (Mestrado) - Programa de Promoção de Saúde, Universidade de Franca, Franca, 2006.

GARCIAS, F.M.; BAGER, A. Estrutura populacional de capivaras na Estação Ecológica do Taim, Brasil, RS. Ciência Rural, v. 39, n. 8, p. 2441-2447, 2009.

JACOMASSA, F.A.F. Atividade, uso de ambientes, comportamento e densidade de capivara Hydrochoerus hydrochaeris (Linnaeus, 1766) (Mammalia: Rodentia: Caviidae) no Pantanal do Miranda, MS. Biodiversidade Pampeana, v. 8, n. 1, p. 46-49, 2010.

LABRUNA, M.B.; KERBER, C.E.; FERREIRA, F.; FACCINI, J.L.H.; DE WAAL, D.T.; GENNARI, S.M. Risk factors to tick infestations and their occurrence on horses in the State of São Paulo, Brazil. Veterinary Parasitology, v. 97, n. 1, p. 1-14, 2001.

MACDONALD, D.W. Dwindling resources and the social behaviour of Capybaras, (Hydrochoerus hydrochaeris) (Mammalia). Journal of Zoology, v. 194, n. 3, p. 371-391, 1981.

MONES, A.; OJASTI, J. Hydrochoerus hydrochaeris. Mammalian Species, n. 264, p. 1-7, 1986.

OLIVEIRA, J.A.; BONVICINO, C.R. Ordem Rodentia. In: REIS, N.R.; PERACHI, A.L.; PEDRO, W.A.; LIMA, I.P. (Eds.) Mamíferos do Brasil. Londrina: Universidade Estadual de Londrina, 2006. p. 351-411.

PEREIRA, H.F.A.; ESTON, M.R. Biologia e manejo de capivaras (Hydrochoerus hydrochaeris) no Parque Estadual Alberto Löfgren, São Paulo, Brasil. Revista do Instituto Florestal, v. 19, n. 1, p. 55-64, 2007.

PEREZ, C.A.; ALMEIDA, A.F.; ALMEIDA, A.; CARVALHO, V.H.B.; BALESTRIN, D.C.; GUIMARÃES, M.S.; COSTA, J.C.; RAMOS, L.A.; ARRUDA-SANTOS, A.D.; MÁXIMOESPÍNDOLA, C.P.; BARROS-BATTESTI, D.M. Carrapatos do gênero Amblyomma (Acari: Ixodidae) e suas relações com os hospedeiros em área endêmica para febre maculosa no estado de São Paulo. Revista Brasileira de Parasitologia Veterinária, v. 17, n. 4, p. 210-217, 2008.

RIBEIRO, K.T.; ROCHA, G.F.S.; SARAIVA, D.G.; ALECI; P.S.; VILELA, D.A.R.; LIMA, P.C.S.; CAMPOS, I.B.; FILIPPO, D.C.; NASCIMENTO, J.S.; CALIC, S.B. Das capivaras e carrapatos a uma proposta de comunicação e manejo no Parque Nacional da Serra do Cipó para redução de riscos à saúde. Oecologia Australis, v. 14, n. 3, p. 668-685, 2010.

ROWE, D.L.; HONEYCUTT, R.L. Phylogenetic relationships, ecological correlates, and molecular evolution within the Cavioidea (Mammalia: Rodentia). Molecular Biology and Evolution, v. 19, n. 3, p. 263-277, 2002. 
SANGIONI, L.A.; HORTA, M.C.; VIANNA, M.C.B.; GENNARI, S.M.; SOARES, R.M.; GALVÃO, M.A.M.; SCHUMAKER, T.T.S.; FERREIRA, F.; VIDOTTO, O.; LABRUNA, M.B. Rickettsial infection in animals and brazilian sppoted fever endemicity. Emerging Infectious Diseases, v. 11, n. 2, p. 255-270, 2005.

SILVA, A.C.S. Zoonozes transmitidas por carrapatos: aspectos regionais e vigilância no vale do Paraíba, Estado de São Paulo. 2009. 95 f. Dissertação (Mestrado) - Faculdade de Saúde Pública, Universidade de São Paulo, São Paulo, 2009.

TOMAZZONI, A.C. Ecologia da capivara (Hydrochoerus hydrochaeris, Linnaeus 1766) (Mammalia, Rodentia) na Reserva Biológica do Lami, sul do Brasil. 2003. 81 f. Dissertação (Mestrado) - Programa de Pós-Graduação em Ecologia, Instituto de Biociências, Universidade Federal do Rio Grande do Sul, Porto Alegre, 2003.

VARGAS, F.C. Estudo comparativo de duas populações de capivaras (Hydrocharetis hydrochaeris) no município de Pirassununga, SP. 2005. 78 f. Dissertação (Mestrado) - Faculdade de Zootecnia e Engenharia de Alimentos, Universidade de São Paulo, Pirassununga, 2005.

VARGAS, F.C.; VARGAS, S.C.; MORO, M.E.G.; SILVA, V.; CARRER, C.R.O. Monitoramento populacional de capivaras (Hydrochaeris hydrochaeris Linnaeus, 1766) em Pirassununga, SP, Brasil. Ciência Rural, v. 37, n. 4, p. 1104-1108, 2007. 